\title{
The Influence of Land Surface Heterogeneities on Cloud Size Development
}

\author{
MALTE RIECK \\ Max Planck Institute for Meteorology, and International Max Planck Research School on \\ Earth System Modelling, Hamburg, Germany \\ CAThy Hohenegger and Chiel C. van HeERwaArden \\ Max Planck Institute for Meteorology, Hamburg, Germany
}

(Manuscript received 31 October 2013, in final form 16 May 2014)

\begin{abstract}
This study analyzes the effects of land surface heterogeneities at various horizontal scales on the transition from shallow to deep convection and on the cloud size distribution. An idealized case of midlatitude summertime convection is simulated by means of large-eddy simulations coupled to an interactive land surface. The transition is accelerated over heterogeneous surfaces. The simulation with an intermediate patch size of $12.8 \mathrm{~km}$ exhibits the fastest transition with a transition time two-thirds that over a homogeneous surface. A similar timing is observed for the precipitation onset whereas the total accumulated rainfall tends to increase with patch size. The cloud size distribution can be approximated by a power law with a scale break. The exponent of the power law is independent of the heterogeneity scale, implying a similar cloud cover between the simulations. In contrast, the scale break varies with patch size. The size of the largest clouds does not scale with the boundary layer height, although their maximum size scales with the patch size. Finally, the idea that larger clouds grow faster, known from homogeneous surface conditions, is not fully valid over heterogeneous surfaces. These various aspects can be understood from the complex interplay between the characteristics of the triggered mesoscale circulations and a cloud development acting in response to the diurnal cycle in surface heating. The results also call for adequate representation of such effects in convective parameterizations.
\end{abstract}

\section{Introduction}

Energy fluxes at the land-atmosphere boundary are spatially heterogeneous as a result of variability in the surface properties. In addition, these exchange processes are also regulated by the atmospheric state. Weather and climate predictions are thus expected to be sensitive to land-atmosphere interactions (e.g., Koster et al. 2004). The diurnal cycle of convection is particularly sensitive to land-atmosphere interactions because convective clouds root in the planetary boundary layer. Several studies performed with large-eddy simulations have investigated the mechanisms controlling the transition from shallow to deep convection (Khairoutdinov and Randall 2006; Kuang and Bretherton 2006; Wu et al. 2009; Hohenegger and Stevens 2013). Khairoutdinov and Randall (2006) as

Corresponding author address: Malte Rieck, Max Planck Institute for Meteorology, Bundesstrasse 53, Hamburg 20146, Germany.

E-mail: malte.rieck@mpimet.mpg.de well as Kuang and Bretherton (2006) suggested that the horizontal widening of clouds as time proceeds is important for the transition to deep convection. Wu et al. (2009) argued that the transition happens when shallow clouds become on average buoyant, and Hohenegger and Stevens (2013) dismissed the idea that moistening by congestus clouds is important for triggering deep clouds. Despite this improved understanding, the diurnal cycle of deep convection remains a major challenge for current weather and climate models with a typically too late onset of precipitation in cloud-resolving models (e.g., Petch et al. 2002; Baldauf et al. 2011; Kühnlein et al. 2014) and too early onset of precipitation in models with parameterized convection (e.g., Bechtold et al. 2004). Moreover the above-mentioned studies have focused on the transition over homogeneous surfaces. In this study the effect of heterogeneous surfaces on the transition is examined.

It has long been known that heterogeneous surface conditions affect the state of the planetary boundary layer, the development of shallow convection, and may influence the amount of convective precipitation. 
Avissar and Schmidt (1998) and others explained the generation of mesoscale circulations as a result of surface heterogeneity. From linear theory it was shown that the circulation strength increases with patch size (Dalu and Pielke 1989). Since then several high-resolution modeling studies with grid spacings ranging from tens to hundreds of meters have been carried out to understand these circulations and their possible importance for shallow convection (Raasch and Harbusch 2001; van Heerwaarden and Vilà-Guerau de Arellano 2008; Garcia-Carreras et al. 2011; Huang and Margulis 2013). The use of high resolution is crucial given the small-scale nature of the simulated phenomena. It has been found that roll-like structures create local areas of convergence associated with strong vertical motion. These circulations are confined by the boundaries of the land surface discontinuities with their strength depending on the amplitude of the surface heterogeneity. Van Heerwaarden and Vilà-Guerau de Arellano (2008) found areas of higher relative humidity over warm patches indicating a higher potential for cloud formation. Huang and Margulis (2013) showed that strongly heterogeneous surfaces yield thicker and deeper shallow convective clouds. Garcia-Carreras et al. (2011) explained the reasons for a preferred location of shallow convective clouds on the front of the mesoscale circulations. Recently, Kang and Bryan (2011) studied the effect of the amplitude of the surface heterogeneity on the transition to deep convection by prescribing sinusoidal surface fluxes of various amplitudes. As the amplitude becomes larger the area of mesoscale convergence becomes narrower and stronger and will lead to an earlier transition to deep convection. Kang and Bryan (2011) suggested local differences in the planetary boundary layer height to explain their results.

Because of the computational costs, three-dimensional high-resolution simulations of deep convection with an interactive land surface model have not yet been performed. Results from two-dimensional or coarser-resolution simulations with partly parameterized convection exist [see Pielke (2001) for a review]. Lynn et al. (1998) especially found that precipitation increases with patch size with a maximum close to the local radius of deformation. Later, using quasi-three-dimensional simulations, Lynn et al. (2001) could not reconfirm a linear relationship between total accumulated rainfall and patch size. However, precipitation varied with the size of the individual patch. Limitations in both domain and grid sizes raise the question whether the effects of surface heterogeneity have been correctly modeled in those earlier studies (see Hohenegger et al. 2009).

Given these various effects of land surface heterogeneities on convection, several authors have also attempted to implement such effects in convective parameterizations.
Lynn et al. (2001) for instance proposed to alter the triggering formulation. Future scale-aware convective parameterizations are expected to make use of the statistical nature of convection by considering an ensemble of clouds and directly predict the time evolution of the cloud size. The eddy diffusivity mass flux scheme (Neggers 2009) or the convection scheme developed by Plant and Craig (2008) may be seen as first attempts in this direction. Recent studies on shallow convection over homogeneous surfaces have shown that the cloud size distribution can be described by a power law with a scale break at the larger clouds (Neggers et al. 2003; Dawe and Austin 2012; Heus and Seifert 2013). Prediction of the correct cloud size is also important for conventional bulk mass flux schemes where the entrainment rate is often implicitly assumed to be inversely proportional to the cloud radius (e.g., Kain 2004).

The goal of this study is to assess and understand the effects of surface heterogeneity on the transition from shallow to deep convection. Of particular interest are possible relationships between (i) the patch size of the surface heterogeneity and the transition time and (ii) the patch size and the cloud size distribution. The cloud size distribution is characterized by the functional shape of its distribution (e.g., power law, exponent of the power law, scale break) and the evolution of its largest cloud. The view that clouds need to grow in (horizontal) size to transition to deep convection, emphasized recently for the development of deep convection over homogeneous surfaces, is adopted. Larger clouds entrain less and can more easily grow deep. The question addressed by this study may thus be reformulated in simple terms as whether and how surface heterogeneities support the formation of larger clouds.

High-resolution, three-dimensional large domain large-eddy simulations coupled to a land surface model are employed. The setup allows an interactive representation of the dynamical interactions between the land surface and the atmosphere including the effect of cloud shading, local circulations, and cold pools on heating and evapotranspiration. An idealized case mimicking the transition from shallow to deep convection over midlatitude continental areas during summer is simulated. Surface heterogeneity with various patch sizes is imposed by varying the leaf area index.

Except for the study by Kang and Bryan (2011), previous studies on the effects of surface heterogeneity have neither focused on the transition phase and the cloud size distribution nor used fully interactive threedimensional large-eddy simulations. The present study differs from the one by Kang and Bryan (2011) in several key points: the model setup is substantially advanced by the use of an interactive land surface, the focus lies on 
the sensitivity to the patch size of the surface heterogeneity and not to its amplitude, and the impact on the cloud size distribution is investigated.

The paper outline is as follows. Section 2 describes the model and experimental setups in more detail. The basic effects of heterogeneous surface conditions on the diurnal cycle of convection, on the mean cloud features, and especially on the transition time are presented in section 3 . The shape and evolution of the cloud size distribution as well as its relationship to the patch size of the surface heterogeneity is discussed in section 4 , followed by a detailed analysis of the underlying mechanisms in section 5 . The summary and conclusions are given in section 6 .

\section{Methodology}

\section{a. The large-eddy simulation model}

The University of California, Los Angeles, large-eddy simulation model (UCLA-LES; Stevens et al. 2005; Savic-Jovcic and Stevens 2008) is used. The model solves the Navier-Stokes equations on a three-dimensional grid in the elastic limit with a third-order Runge-Kutta integration in time. Lateral boundary conditions are cyclic whereas the model top is buffered with a damping layer to absorb propagating waves. Subgrid fluctuations of scalars and momentum are parameterized using the Smagorinsky closure. To ensure suitable model physics for the simulation of deep convection, comprehensive schemes are employed to parameterize cloud microphysics and radiation. The two-moment cloud microphysics scheme of Seifert and Beheng (2006), which includes cloud water, rain, ice, graupel, hail, and snow is used. The radiative transfer is modeled with a delta fourstream method following Pincus and Stevens (2009). In this context, the radiation model has been updated to represent the effects of ice clouds on radiative properties following $\mathrm{Fu}$ and Liou (1993). This modeling framework has been tested and successfully applied to simulate the diurnal cycle of deep convection over oceanic tropical areas in Hohenegger and Stevens (2013) and continental midlatitude areas in Schlemmer and Hohenegger (2014).

For the purpose of this study the UCLA-LES has been coupled to a land surface model (LSM). The LSM is adopted from the Dutch Atmospheric LES (DALES) as described in Heus et al. (2010). Fluxes between the land and the atmosphere are calculated interactively solving the linearized version of the surface energy balance [Eq. (1)] for each grid cell at every time step:

$$
C_{s} \frac{d T_{s}}{d t}=Q_{\text {net }}-F_{\text {sens }}-F_{\text {lat }}-F_{\text {soil }} .
$$

A skin layer between land and atmosphere represents the vegetation characterized by its heat capacity $C_{s}$ and surface temperature $T_{s}$. At the surface the radiative fluxes $Q_{\text {net }}$ are averaged in time to avoid short-term fluctuations in the surface temperature due to the use of Monte Carlo sampling in the radiation code, a problem described in Pincus and Stevens (2013). Given the employed background wind of $0.5 \mathrm{~m} \mathrm{~s}^{-1}$ and horizontal resolution of $100 \mathrm{~m}$, an averaging period of $100 \mathrm{~s}$, corresponding to a travel distance of $50 \mathrm{~m}$ (half the horizontal resolution), is chosen.

The variables $F_{\text {sens }}, F_{\text {lat }}$, and $F_{\text {soil }}$ represent the sensible, latent, and ground heat flux, respectively; $F_{\text {sens }}$ and $F_{\text {lat }}$ are parameterized as

$$
\begin{gathered}
F_{\text {sens }}=\frac{\rho c_{p}}{r_{a}}\left(\theta_{s}-\theta_{\mathrm{atm}}\right) \quad \text { and } \\
F_{\text {lat }}=\frac{\rho L_{v}}{r_{a}+r_{s}}\left[q_{\mathrm{sat}}\left(\theta_{s}\right)-q_{\mathrm{atm}}\right],
\end{gathered}
$$

where $\theta_{s}$ and $\theta_{\text {atm }}$ are the potential temperatures at the surface and at the first atmospheric model level, respectively; $r_{a}$ is the aerodynamic resistance; $r_{s}$ is the surface resistance; $q_{\mathrm{sat}}\left(\theta_{s}\right)$ is the saturation specific humidity at the surface; $q_{\mathrm{atm}}$ is the specific humidity at the first atmospheric level; $\rho$ is the density of air; $c_{p}$ is the specific heat capacity of the air at constant pressure; and $L_{v}$ is the specific heat of vaporization.

A resistance formulation is employed to include the control of the land surface and of the atmosphere on the exchange of heat and moisture; $r_{a}$ is determined from the drag coefficient for heat and the wind speed at the lowest model level. Here, Monin-Obukhov similarity theory is used to calculate the drag coefficient. The surface resistance $r_{s}$ is calculated following the JarvisStewart parameterization (Jarvis 1976) for vegetated surfaces and depends on the leaf area index (LAI), the incoming shortwave radiation, the soil moisture content, the vapor pressure deficit, and the surface temperature.

The skin layer is coupled to a four-layer diffusive soil scheme to advance the soil temperature and soil moisture in time. As a lower boundary condition the soil model has a prescribed climatological mean temperature and moisture. The thickness of the soil layers $\Delta z_{i}$ decreases from the lowest level toward the surface $\left(\Delta z_{i}\right.$ : $1.39,1.13,0.27,0.07 \mathrm{~m}$ ). Because of the thin top soil layer and the small heat capacity of the skin layer this setup is able to capture the dynamical interactions that arise between the land surface and the atmosphere.

The model setup has been validated against DALES for a case of a dry convective boundary layer and against a formulation with fixed sea surface temperature and prescribed drag coefficients for a case of shallow cumulus convection over the ocean. In both cases the UCLA-LES coupled to the LSM was able to reproduce the sensible 

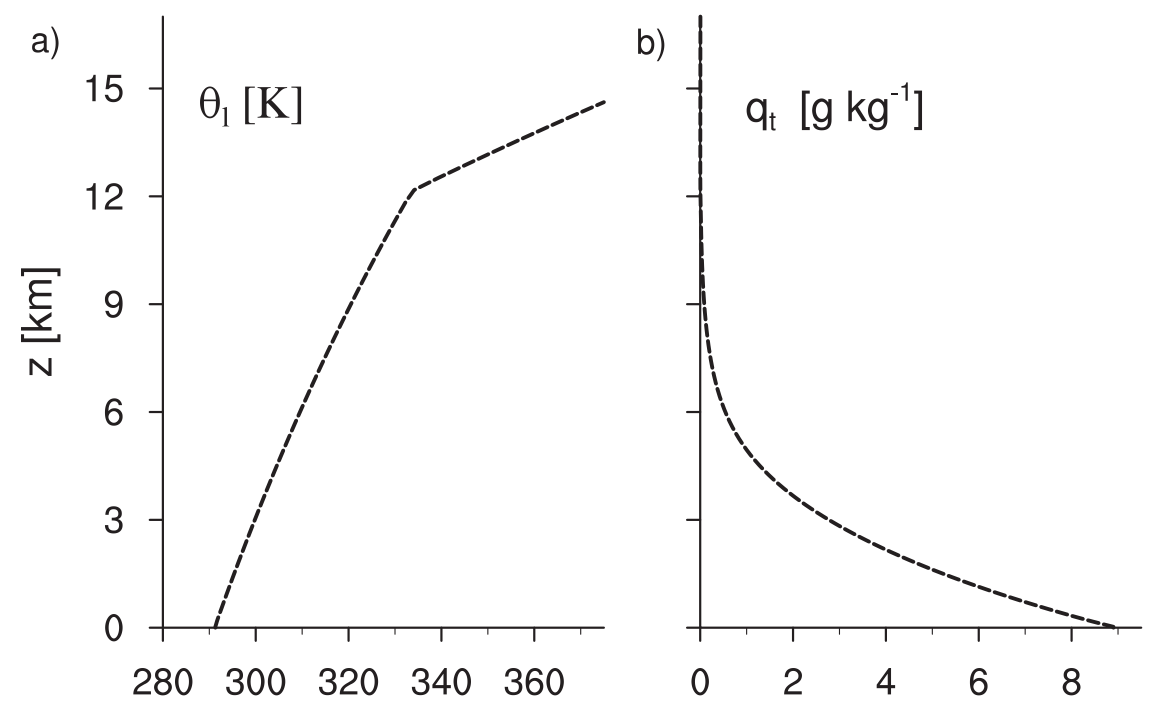

FIG. 1. Initial profile of (a) liquid water potential temperature $\theta_{l}$ and (b) total water specific humidity $q_{t}$.

and latent heat fluxes of DALES resulting in a very similar boundary layer structure and cloud evolution (not shown). Further validation in terms of the expected development of deep convection over land is given in section 3 .

\section{b. The experiments}

The UCLA-LES is employed to simulate the transition from shallow to deep convection over midlatitude continental area during summer. The computational domain spans $1024 \times 1024 \times 118$ grid points with an isotropic horizontal grid spacing of $100 \mathrm{~m}$. In the vertical a stretched grid ranging from $\Delta z=50 \mathrm{~m}$ in the lowest boundary layers up to $\Delta z=500 \mathrm{~m}$ near the tropopause is used.

This study uses initial conditions from Schlemmer et al. (2011) representative for midlatitude summertime convection. The atmospheric dataset is taken from radio soundings around Munich, Germany, and from zonal mean climatologies for summertime conditions at $48^{\circ} \mathrm{N}$. Our experiments nevertheless differ in a few key points. First, because of computational limitations in this study we simulate only one diurnal cycle instead of an equilibrium diurnal cycle that is averaged over 30 consecutive days. Second, a uniform and height-independent background wind of $0.5 \mathrm{~m} \mathrm{~s}^{-1}$ is prescribed. Third, heterogeneous surface conditions are considered. Finally and most importantly, the horizontal resolution amounts to $100 \mathrm{~m}$ instead of $2.2 \mathrm{~km}$, meaning that both shallow and deep convection can be explicitly resolved.

Figure 1 shows initial profiles of liquid water potential temperature and total water specific humidity used in this study. The liquid water potential temperature linearly increases up to the tropopause at $12.8 \mathrm{~km}$ followed by a much stronger increase. This translates into a tropospheric lapse rate of absolute temperature of $6.8 \mathrm{~K} \mathrm{~km}^{-1}$. The specific humidity decays exponentially with height, resulting in a relative humidity of $68 \%$ in the lower atmosphere and $40 \%$ at $5.5 \mathrm{~km}$ height.

The skin layer is characterized by a vegetated surface and initialized with a surface temperature of $291 \mathrm{~K}$. The surface roughness length for momentum is set to 0.04 and $0.008 \mathrm{~m}$ for heat, respectively. The soil is classified as loam with a wilting point of $0.171 \mathrm{~m}^{3} \mathrm{~m}^{-3}$ and a field capacity of $0.323 \mathrm{~m}^{3} \mathrm{~m}^{-3}$. The upper three soil levels are initialized with a soil moisture content of $0.27 \mathrm{~m}^{3} \mathrm{~m}^{-3}$ (about $85 \%$ saturation of field capacity) and a temperature in equilibrium with the skin and first atmospheric layer. The soil initial state is thought to represent continental midlatitude conditions, and is similar to the CONTROL case presented in Schlemmer et al. (2011).

Six experiments are performed (see Table 1). Five of them employ heterogeneous surface conditions with a fixed patch size. The heterogeneity at the surface is prescribed exclusively by varying the LAI in a checkerboard pattern. For this purpose a fixed LAI of 2.0 and 6.0 is used. The above-mentioned patch size thus refers to the size of one such patch of constant LAI. Changes in LAI induce changes in sensible and latent heat flux between the patches (see Fig. 2). All other surface conditions are held constant across the patches. The chosen specification of the surface heterogeneity is thus not meant to represent realistic surface conditions but to understand the effects of surface heterogeneity in a simple and idealized setup. Despite this idealization it is important to note that the modeled surface fluxes are in the order of magnitude of measurements over grassland for various FLUXNET 
TABLE 1. Summary of the performed experiments with experiment name, patch size, local time of transition to deep convection, local time of breeze front collision, and domain mean precipitation averaged over the simulation period. The transition time is determined from profile statistics sampled every $60 \mathrm{~s}$. The collision time is diagnosed from vertical cross sections showing horizontal (as displayed in Fig. 8) and vertical wind sampled from 3D data every $30 \mathrm{~min}$.

\begin{tabular}{lcccc}
\hline \hline Expt name & $\begin{array}{c}\text { Patch } \\
\text { size }(\mathrm{km})\end{array}$ & $\begin{array}{c}t_{\text {transition }} \\
(\mathrm{LST})\end{array}$ & $\begin{array}{c}t_{\text {collision }} \\
(\mathrm{LST})\end{array}$ & $\begin{array}{c}\text { Precipitation } \\
\left(\mathrm{mm} \mathrm{day}^{-1}\right)\end{array}$ \\
\hline HOM & - & 1215 & - & 1.12 \\
HET-XS & 3.2 & 1205 & - & 0.94 \\
HET-S & 6.4 & 1135 & 1030 & 1.17 \\
HET-M & 12.8 & 1100 & 1130 & 1.60 \\
HET-L & 25.6 & 1104 & 1300 & 1.45 \\
HET-XL & 51.2 & 1120 & 1330 & 1.87 \\
\hline
\end{tabular}

sites in central Europe [see Fig. 2 in Teuling et al. (2010)]. The differences in surface fluxes between the two surfaces types may be caused by varying the vegetative situation or the soil moisture. Similar flux variations were observed over cropland with different LAI during the Soil Moisture-Atmosphere Coupling Experiment (SMACEX) campaign [see Table 4 in Su et al. (2005)].

The sixth simulation employs homogeneous surface conditions (HOM). The LSM is switched off and the surface fluxes are prescribed by averaging the surface fluxes of HET-XS. Although HOM has no interactive surface, this technique assures comparability with the HET experiments since all simulations experience the same mean energy input as long as the cloud cover remains similar (not shown). This is especially true during the transition phase (see e.g., Fig. 4a).

\section{Main features and transition times}

In the land-atmosphere system the surface fluxes of heat and moisture closely follow the incoming net radiation with the surface determining their partition. The available incoming net radiation reaches its maximum at 1200 local standard time (LST) resulting in domain mean average latent and sensible heat fluxes of 374 and $145 \mathrm{~W} \mathrm{~m}^{-2}$ respectively. These values are akin to the ones obtained in Schlemmer et al. (2011) for a similar but homogeneous case simulated with the Consortium for Small-Scale Modeling (COSMO) model.

Figure 2 shows the horizontal distribution of the surface fluxes at 1100 LST. Alternating warm and dry and cold and wet patches can be recognized. The displayed checkerboard pattern mirrors the imposed surface heterogeneity in spite of the influence of turbulence, clouds, and the developing near-surface anomalies in atmospheric temperature and moisture. In HET-XL, the sensible heat flux is $40 \mathrm{~W} \mathrm{~m}^{-2}$ higher over the warm than

$$
\text { 容 }
$$
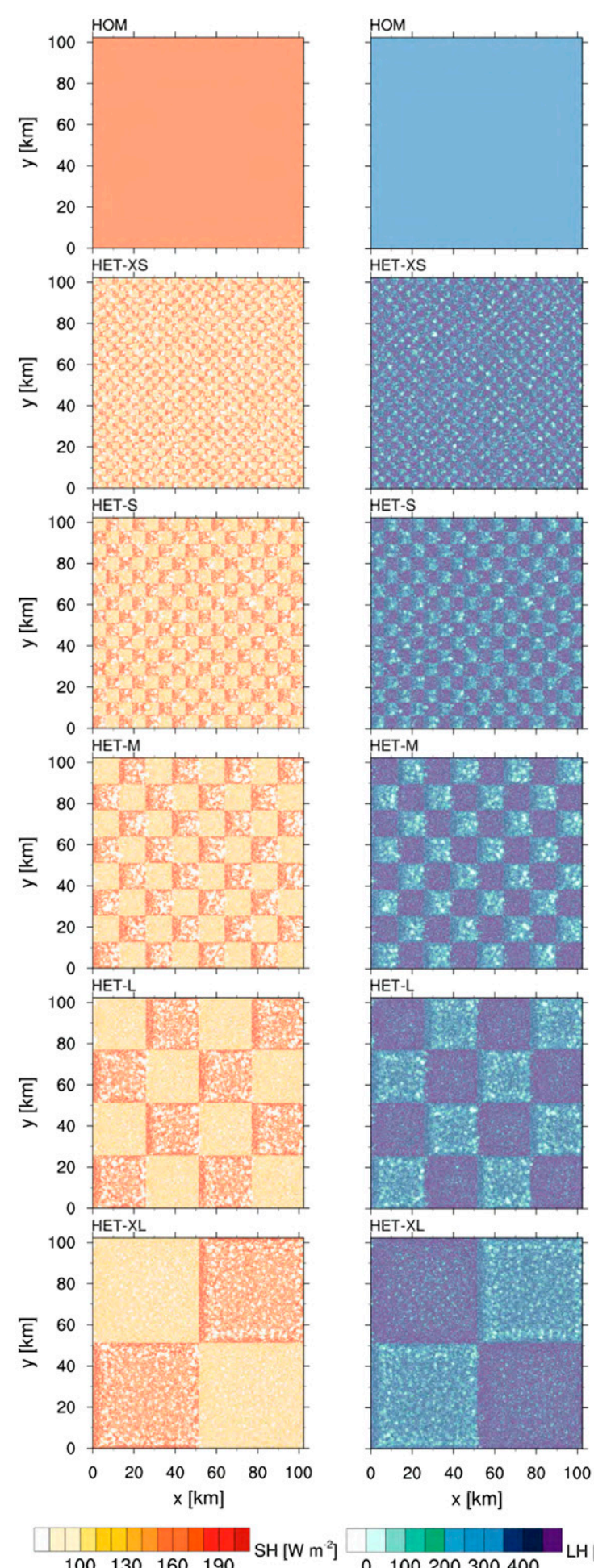

HET-XS

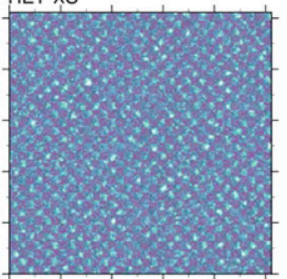

HET-S

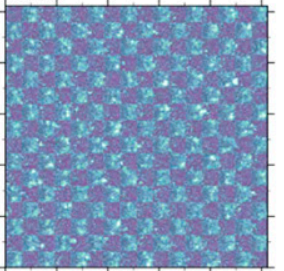

HET-M

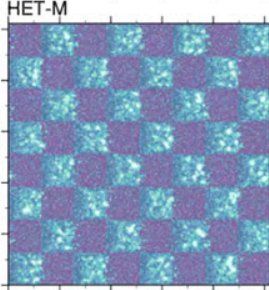

HET-L

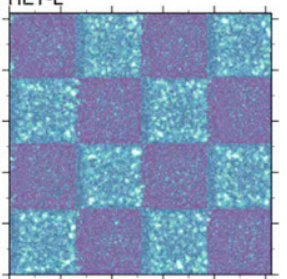

HET-XL

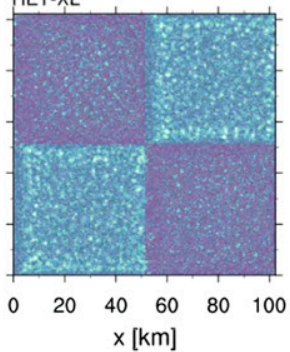

100130160190

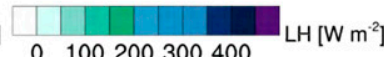

FIG. 2. Horizontal view of the surface fluxes-(left) sensible and (right) latent heat-in the different experiments at 1100 LST. 


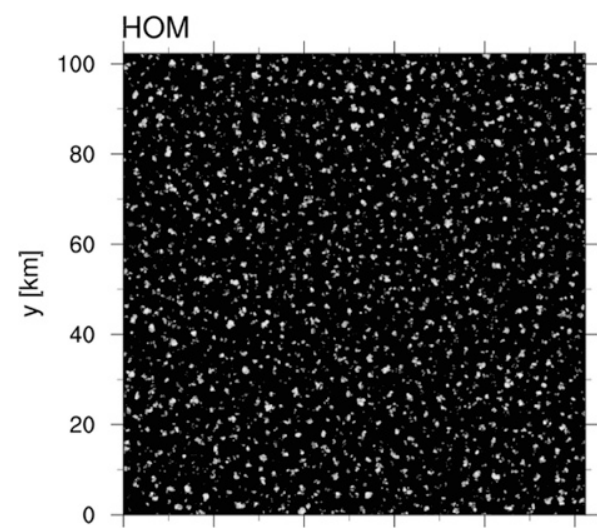

HET-XS
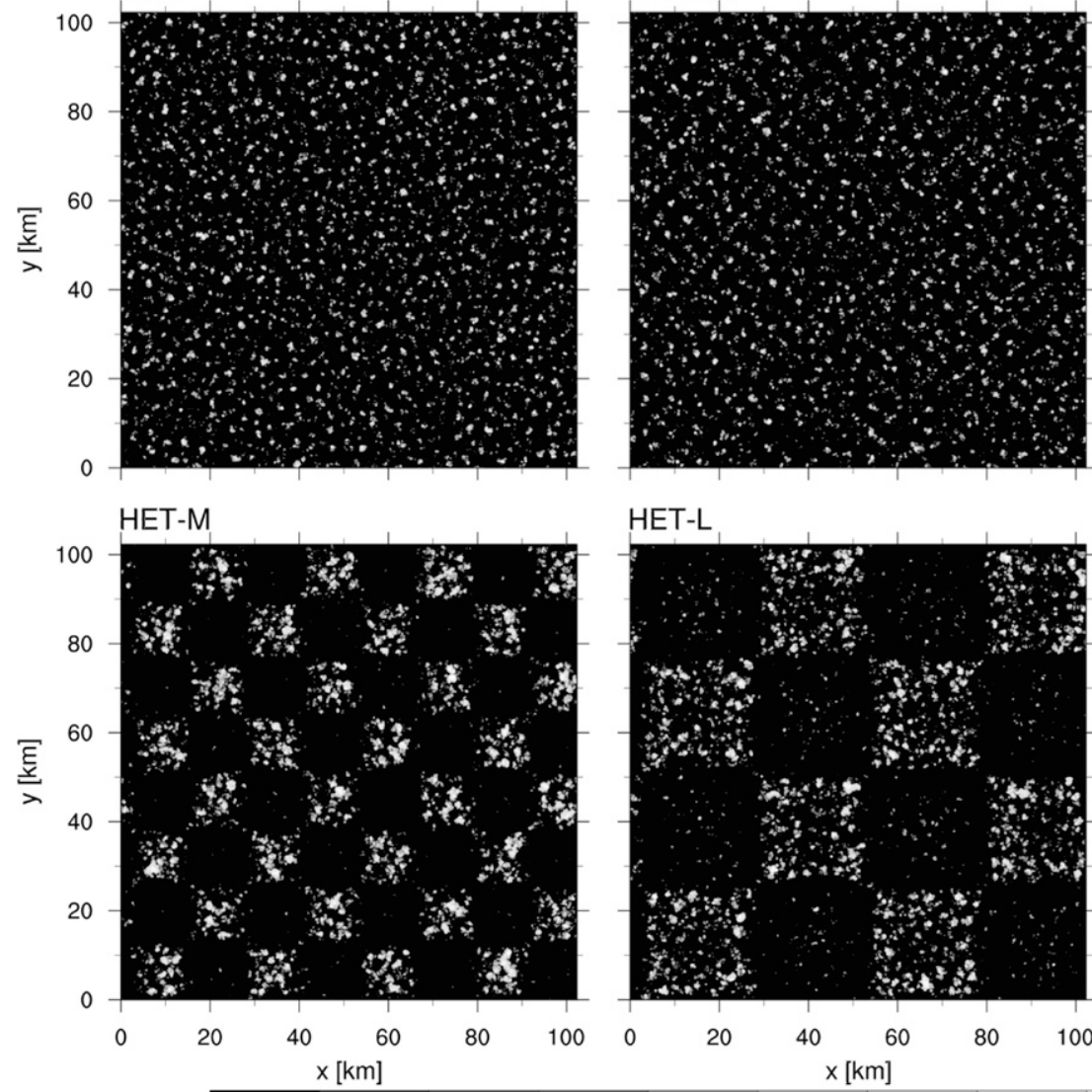

HET-L
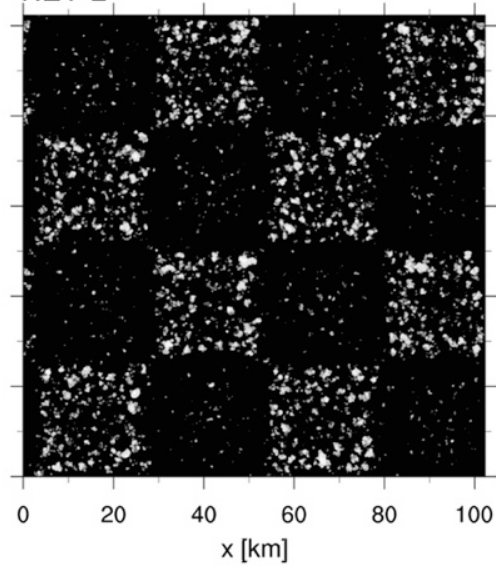

HET-S

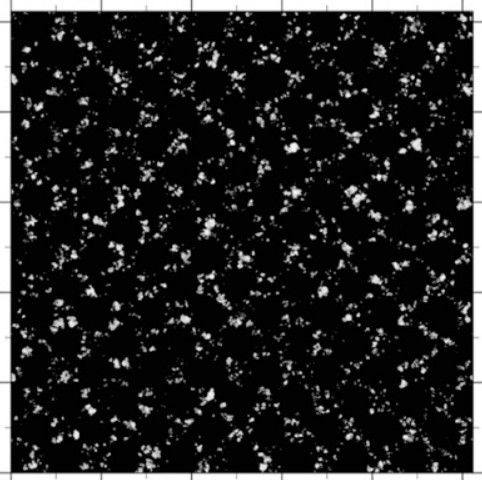

HET-XL

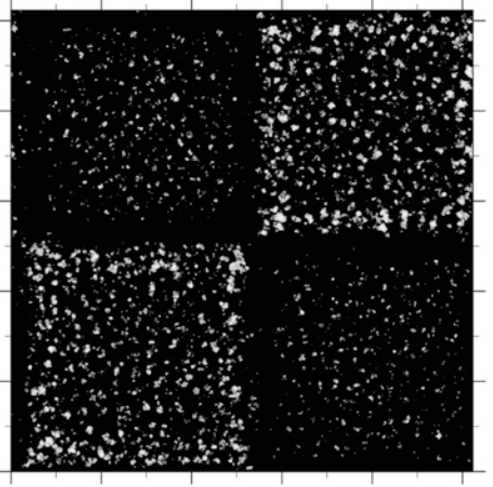

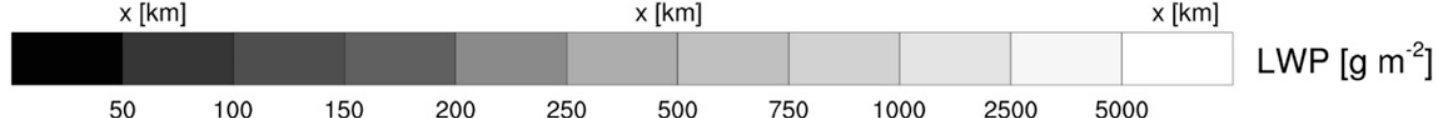

50

FIG. 3. Instantaneous view of the cloud field in terms of liquid water path in the different experiments at 1100 LST.

over the cold patch whereas the latent heat flux is $122 \mathrm{~W} \mathrm{~m}^{-2}$ higher over the cold than over the warm patch. The corresponding mean Bowen ratios are 0.59 for the warmer and 0.32 for the colder patch, indicating a higher potential for turbulence and stronger updrafts over the warmer patch.

Although the use of an interactive LSM does not mask the imposed pattern in surface heterogeneity, one effect is clearly visible in Fig. 2. The lighter spots visible on the warm patches, both on the sensible and latent heat flux, mark the location of clouds (cf. Figs. 2 and 3). The effect of cloud shading can be quantified by comparing the fluxes for cloudy and noncloudy points. In HET-XL at 1100 LST the presence of clouds over the warm patch reduces the sensible heat flux by $12 \mathrm{~W} \mathrm{~m}^{-2}$ whereas the reduction is only $2 \mathrm{~W} \mathrm{~m}^{-2}$ over the cold patch. Since most of the clouds are located above the warm patch, the shading effect decreases the difference in surface sensible heat fluxes between the two surface types by $20 \%$ $\left(\Delta \mathrm{SH}_{\text {clearsky }}=50 \mathrm{~W} \mathrm{~m}^{-2}\right.$ and $\left.\Delta \mathrm{SH}_{\text {allsky }}=40 \mathrm{~W} \mathrm{~m}^{-2}\right)$. This suggests that models without interactive land surface may overestimate both local surface fluxes and the horizontal gradient due to surface heterogeneities and consequently produce too strong mesoscale circulations. These effects are expected to be larger for situations with higher cloud cover and cloud albedo. The attenuation of the available net incoming radiation by clouds is independent of the patch size as long as the cloud cover remains constant across the simulations (see Fig. 4a), which is the case up to about 1200 LST.

Figure 3 shows the horizontal distribution of the liquid water path at 1100 LST for the various experiments. The signature of the surface heterogeneity is again clearly visible. Cloud formation happens predominantly over the warm and dry patches. This effect has been discussed for different cases of summertime convection over heterogeneous land surfaces (Avissar and Schmidt 1998; Kang and Bryan 2011; Garcia-Carreras et al. 2011). Clouds form when strong thermals penetrate the boundary layer and reach their lifting condensation level. Conditions for cloud formation can be more favorable over warm patches in the sense that thermals are stronger, the boundary layer 

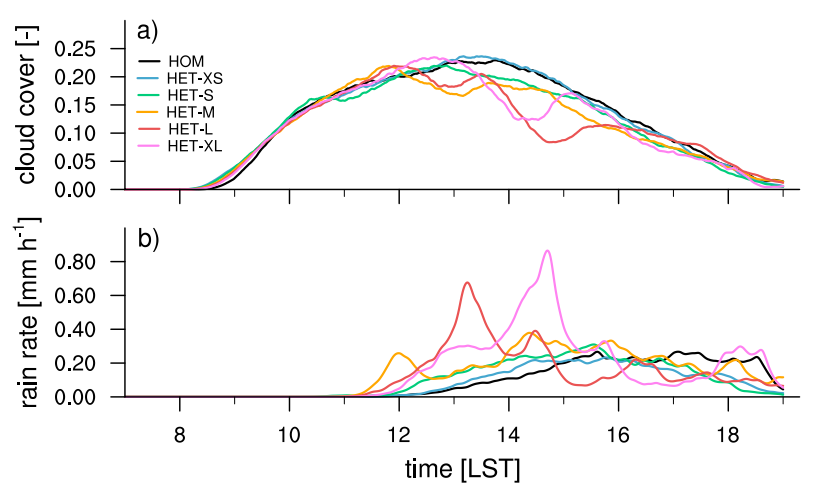

FIG. 4. Time series of domain-averaged (a) cloud cover and (b) surface rain rate.

is deeper, and convective inhibition is reduced. Additionally, mesoscale circulations intensify cloud formation along the warm side of patch boundaries. The effect of mesoscale circulations on the timing and size distribution of the convective clouds is discussed in section 5 .

The time evolution of cloud cover and rain rate is shown in Fig. 4. All the simulations exhibit a similar and realistic diurnal cycle of convection. At 0800 LST thermals start penetrating the convective boundary layer. Shallow clouds appear shortly thereafter and grow deeper causing a rapid increase in cloud cover of up to $20 \%$ around noon (Fig. 4a). Convective clouds are triggered in response to the increasing instability (surface warming) and disappear in the evening when the surface forcing ceases. Convective precipitation starts around noon and peaks later in the afternoon (Fig. 4b).

A similar behavior was found in Schlemmer et al. (2011). Both the onset of clouds and of precipitation nevertheless occurs more rapidly in HOM as compared to the CONTROL simulation of Schlemmer et al. (2011). The precipitation amounts are also smaller in HOM whereas the time of peak precipitation remains identical. A major difference between the two studies (see section $2 b$ ) is the model resolution. Shallow convection is explicitly resolved in UCLA-LES whereas the COSMO grid size is too coarse to explicitly resolve all shallow clouds. This may in part explain the later start of precipitation in COSMO, a common issue in cloud-resolving models (Petch et al. 2002; Baldauf et al. 2011; Kühnlein et al. 2014). Furthermore, both models employ a different microphysics scheme. Other differences (e.g., the surface fluxes calculated from different LSMs or the domain size) may further explain the discrepancies between the two experiments. Given these differences in the modeling setup the obtained results remain remarkably similar and give confidence that they are representative for midlatitude summertime convection.
Comparison of the different simulations in Fig. 4a indicates that the cloud cover remains similar as long as no precipitation is falling. Precipitation is an efficient mechanism to remove moisture from the atmosphere so that changes in precipitation rates tend to result in changes in cloud cover. The cloud cover is mainly determined by the smaller clouds due to their abundance (see Wood and Field 2011). As will be shown in section 4, the distribution of these small clouds remains similar between the experiments before strong precipitation sets in. The time of cloud onset is barely influenced by the patch size. The use of a relatively moist initial profile may limit the impact of surface heterogeneity in this regard.

In contrast to Fig. 4a the timing and strength of the surface precipitation varies clearly with patch size (Fig. 4b). Here, HET-M begins to precipitate before HET-L followed by HET-XL, HET-S, HET-XS, and HOM whereby HET-XS and HOM exhibit a very similar time series. Although the patch size clearly influences the timing of precipitation, there is no linear relationship between the time of precipitation onset and the patch size (see further below). The differences in timing between the simulations are more visible in the precipitation time series than in the cloud cover because precipitation formation is a slower process. The domain mean precipitation averaged over the full simulation period generally increases with increasing patch size (see Table 1). The domain mean precipitation is largest in HET-XL with a $67 \%$ increase compared to HOM. The obtained changes in precipitation with patch size confirm the results from two-dimensional cloud resolving simulations as presented by Lynn et al. (1998). In their case the precipitation also tended to increase with patch size. A simulation with a patch size of $64 \mathrm{~km}$ yielded an increase by about $60 \%$ compared to a simulation with homogeneous surface conditions (from a visual inspection of their Fig. 10). Chen and Avissar (1994) furthermore reported an increase in precipitation with patch size. Both studies attributed this behavior to the dependency of the triggered mesoscale circulation on the imposed perturbation scale as reported by Dalu and Pielke (1989). Linearization of the equation of motion indicates that the strongest circulations are obtained when the scale of the imposed perturbation equals the size of the local Rossby radius of deformation, which is about $100 \mathrm{~km}$ in midlatitudes. By studying the response of the convection to a localized source of heating, Robinson et al. (2008) proposed an alternate explanation and argued that the strongest response of convection should be obtained when the aspect ratio of the applied heating matches the ratio of vertical and horizontal wavenumbers demanded by the dispersion relation for buoyancy waves. This scale was found to be $50 \mathrm{~km}$, which is equivalent to 
the patch size of HET-XL. Hence, both explanations support the results of Table 1, that is, the largest domain mean precipitation for HET-XL given the considered patch sizes.

To assess the transition from shallow to deep convection more quantitatively, mean profiles of cloud condensate and precipitation are sampled and displayed in Fig. 5. All experiments show a gradual increase of cloud depth with time until they finally transition to deep convection. The transition time is defined as the time when the mean cloud condensate exceeds $1 \mathrm{mg} \mathrm{kg}^{-1}$ at $5.5-\mathrm{km}$ height for at least $10 \mathrm{~min}$. Other choices give different transition times but do not fundamentally alter the main differences between the simulations. From now on, the word shallow (deep) is reserved to characterize the convection before (after) the diagnosed transition time.

The transition time substantially differs among the experiments (see Fig. 5 and Table 1). The transition tends to occur faster with increasing patch size, although HET-M exhibits the fastest transition. The behavior is similar to the behavior of the onset time of precipitation, confirming Fig. 4a. The transition is already completed at 1100 LST in HET-M whereas it takes $1.25 \mathrm{~h}$ longer in HOM. Given that the transition is a fast process, taking only $2.5 \mathrm{~h}$ in HET-M, a difference of $1.25 \mathrm{~h}$, half the transition time, is not negligible. These differences in transition time can be understood by considering the cloud size distribution and its relationship to the patch size as explained in the next sections.

\section{The cloud size distribution}

To determine the cloud size distribution and link it to the patch size, we derive the size of the clouds from the simulation statistics. We follow the approach taken in previous studies (e.g., Neggers et al. 2003). Cloud clusters are first defined based on the value of the liquid water path. A cloud cluster represents a connected area of points where the liquid water path exceeds $50 \mathrm{~g} \mathrm{~m}^{-2}$. This minimum threshold is used to exclude very thin clouds. This prevents deep convective outflow as well as cloud haze from being counted as convective cloud. Because the liquid water path is a vertically integrated quantity such a cloud cluster describes the vertically projected area of a cloud. The phrase "cloud size" then refers to the horizontal extent of a cloud cluster. It is determined as the diameter of a circle that has the same area as the cloud cluster. This method assumes all clouds being circular irrespective of the actual shape, the cloud overlap, as well as the splitting and merging in time. From visual inspection of the horizontally projected cloud field we are convinced the approximation that

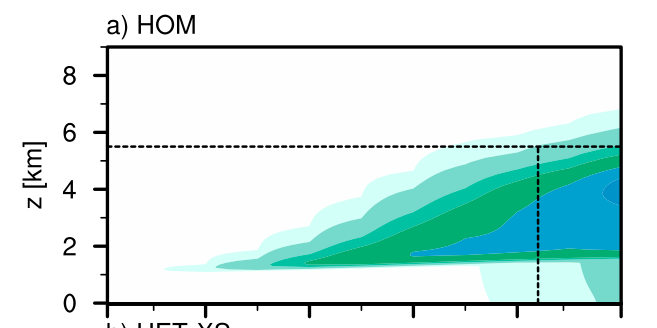

b) HET-XS
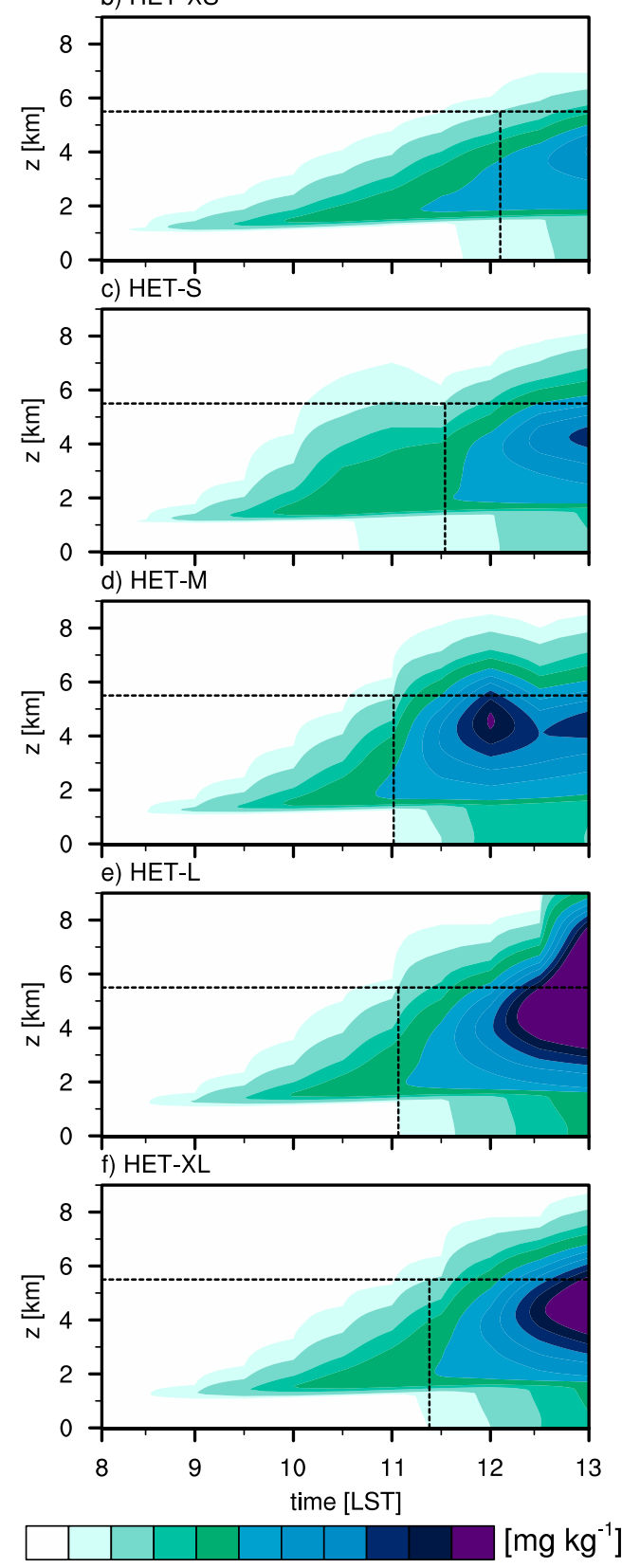

0.11510203040506070

FIG. 5. (a)-(f) Domain-averaged vertical profiles of cloud condensate for all experiments (condensate includes liquid water, ice, snow, hail, graupel, and rain). Vertical dashed lines denote transition time, where the cloud condensate exceeds $1 \mathrm{mg} \mathrm{kg}^{-1}$ at $5.5-\mathrm{km}_{\text {height. }}$ 

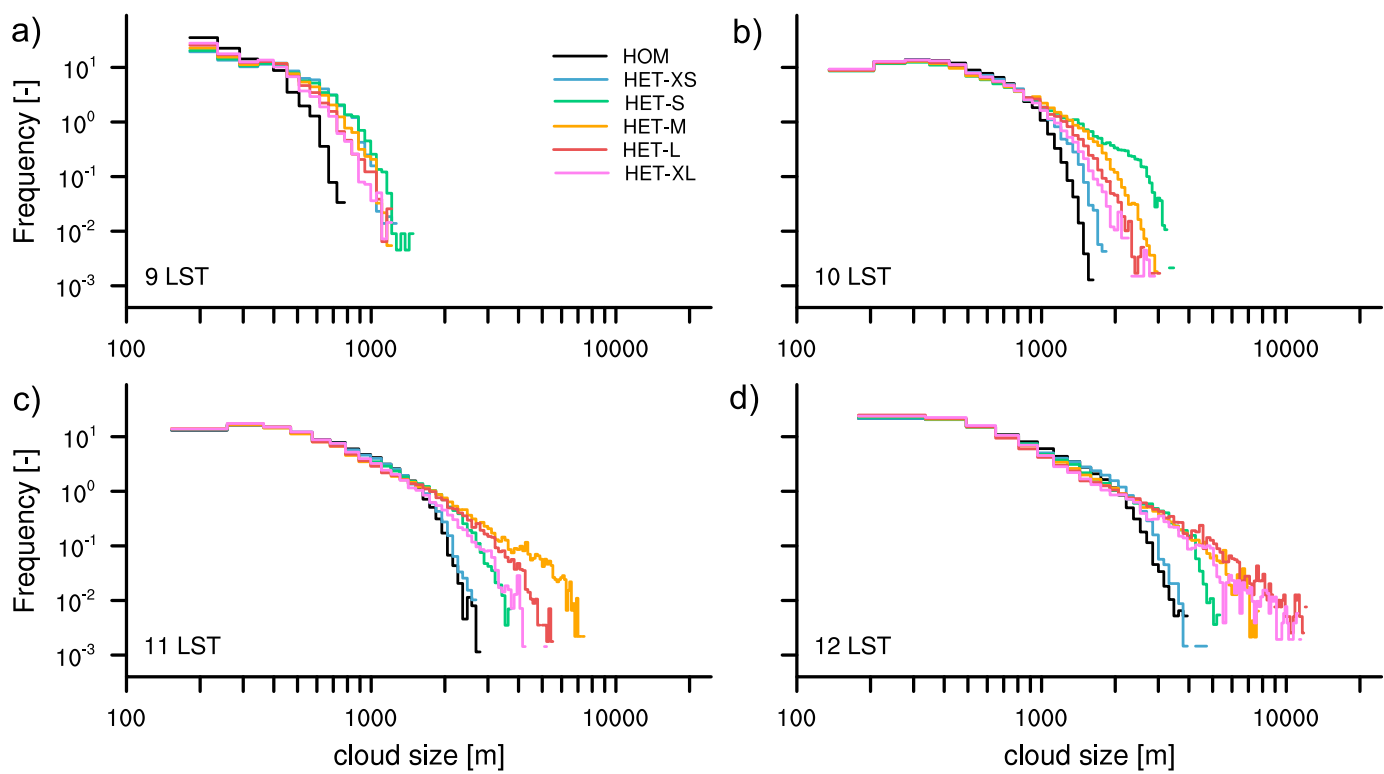

FIG. 6. (a)-(d) Cloud size distribution for the various experiments at different times. The distributions are calculated from instantaneous values of the liquid water path sampled every $60 \mathrm{~s}$ and the distributions are averaged over $30 \mathrm{~min}$. The same bin width is used among the various experiments. The bin width increases with time to account for the growing cloud population.

clouds have a circular shape is a good one. The socomputed cloud size can be quite large as one cloud may contain several convective cores as long as they are connected in space. The liquid water path is sampled every $60 \mathrm{~s}$ yielding comprehensive time series statistics. In most of the shallow and deep convective phase the domain cloud number exceeds 1000 objects at a given time. To increase sample size the distributions are calculated from data considering the cloud population within intervals of $30 \mathrm{~min}$.

Figure 6 shows the cloud size distributions for all experiments from 0900 to 1200 LST (i.e., during the transition phase). The distributions are displayed in a logarithmic scale. Previous studies based on shallow convection over homogeneous surfaces have indicated that the cloud size distribution can be approximated by a power law with a specific scale break at the largest clouds (Neggers et al. 2003; Dawe and Austin 2012; Heus and Seifert 2013). The cloud size density $N(D)$ ranging from the smallest clouds to the scale break follows the form of

$$
N(D) \propto D^{b}
$$

The scale break denotes the scale at which $N(D)$ departs from the power law as given in Eq. (4). Unlike in earlier studies, in this study the cloud size statistics do not converge with time since convection is transitioning from shallow to deep. As a consequence the characteristics of the size distribution, the power-law exponent and the scale break may differ both in time and between the experiments. Neggers et al. (2003), Dawe and Austin (2012), and Heus and Seifert (2013) obtained power-law exponents for shallow cumulus convection that are spread around $b=-1.7,-1.9$, and -2.5 , respectively.

In the early shallow phase around 0900 LST (Fig. 6a), the distribution is generally narrow with almost all clouds being smaller than $1 \mathrm{~km}$. Here, the HET experiments exhibit wider distributions with a maximum cloud size larger by $0.3 \mathrm{~km}$ as compared to HOM. Experiments with smaller patch sizes (HET-XS, HET-S) promote slightly larger clouds. The differences are nevertheless rather small so that, to a first approximation, all HET simulations exhibit a similar size distribution. At 1000 LST the distributions have advanced toward larger cloud sizes, showing a power-law scaling between 0.3 - and $1-\mathrm{km}$ cloud size. All curves have a similar shape in this range with a power-law exponent around $b=-1.9$. At this time of simulation HET-S shows the largest clouds with a scale break around $3 \mathrm{~km}$ against $1.5 \mathrm{~km}$ for HOM. The snapshots at 1100 and 1200 LST show similar behavior; that is, a cloud ensemble that continues to grow, a similar powerlaw behavior at the smaller scales, and distinct scale breaks. At 1200 LST the experiments with the larger patch sizes (HET-M, HET-L, HET-XL) have completed the transition from shallow to deep convection. A distinct scale break is barely visible and cloud sizes in the range from 0.2 to $10 \mathrm{~km}$ follow a power law with an exponent 
around $b=-2.2$ (Fig. 6d). The results (Fig. 6) thus demonstrate that there is no clear dependency of the power-law exponent of the cloud size distribution on the patch size. The effect of the patch size on the cloud size distribution is only visible in the scale break. Since the experiments with larger patch sizes (HET-M, HET-L, HET-XL) tend to transition earlier, the distribution is more rapidly shifted to larger cloud sizes and the scale break at a given time differs.

Figure 6 reveals another important difference between the cloud size evolution over homogeneous and heterogeneous surface conditions. Studies on the transition to deep convection performed with large-eddy simulations over homogeneous surface conditions have indicated that larger clouds grow deeper due to reduced lateral mixing with their environment and that this effect is important in promoting the transition to deep convection. This implies that a simulation with initially larger clouds should transition faster to deep convection. This is clearly not the case in Fig. 6. Although HET-S displays the largest clouds at 1000 LST, it is overtaken by HET-M at 1100 LST, which is itself overtaken by HET-L and HET-XL at 1200 LST. In a heterogeneous environment, a simulation with the largest clouds at a given time may not transition faster to deep convection than another one. The growth of the larger clouds must be limited by some other process (see the next section).

To further understand this behavior the largest clouds are sampled. The resulting time series is shown in Fig. 7a. Starting with a size below $1 \mathrm{~km}$ the largest clouds grows up to a size between 6 and $22 \mathrm{~km}$. The growth rate, however, depends both on the patch size and time. In HOM the growth rate of the largest cloud is rather constant in time. The size ranges from $0.5 \mathrm{~km}$ at $0830 \mathrm{LST}$ to $5.2 \mathrm{~km}$ at 1230 LST. This suggests a smooth and unperturbed life cycle from shallow to deep convection in response to the diurnal cycle of surface heating. Looking at HET-XS, a similar behavior is observed. In HET-S clouds grow more rapidly up to a size of $3.5 \mathrm{~km}$ at 1000 LST followed by a slow decline in size until 1100 LST. A similar effect is visible in HET-M. The cloud size increases up to $7.5 \mathrm{~km}$ at 1130 LST before slightly decreasing until 1230 LST. At this time HET-L has caught up and exhibits the largest maximum cloud size of $12 \mathrm{~km}$. Finally, at 1400 LST, HETXL displays the largest cloud with a size of $22 \mathrm{~km}$. Overall, the experiments with larger patch sizes end up producing much larger clouds. Although the local maximum in the size of the largest clouds increases with patch size, its ratio to the patch size stays constant. This ratio amounts to onehalf of the patch size. This ratio may vary depending on the atmospheric conditions. Nevertheless, it is to be expected to scale with the patch size since the maximum size a cloud may reach is limited by the size of a single patch.
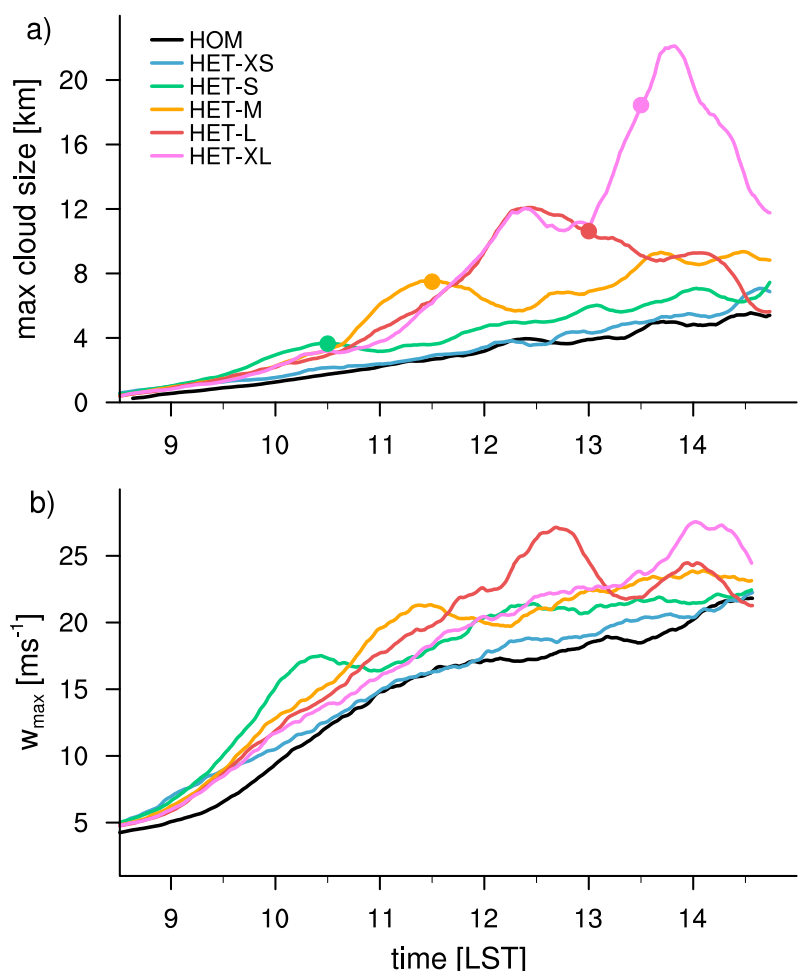

FIG. 7. (a) Time series of the maximum cloud size for all experiments and (b) domain maximum vertical velocity. Cloud statistics and vertical velocity are sampled every $60 \mathrm{~s}$, applying a 20-min running mean. The collision time is denoted by marker points.

Although the cloud evolution may appear different at first sight, Fig. 7a emphasizes a consistent behavior across all simulations consisting of two phases: a phase of above-normal growth rate into a local maximum and a return back toward the original growth rate. This behavior suggests a preferred time and length scale for cloud development over heterogeneous land surfaces. Reasons are given in the next section.

\section{Mechanisms generating the cloud size distribution}

To demonstrate the proposed effect of land surface heterogeneities in generating the cloud size distribution, the transition period between 0900 and 1200 LST is analyzed in more detail.

Figure 8 shows vertical cross sections through the cloud field in the $x$ direction at 1100 LST. All quantities at a given $x$ location are averaged in $y$ direction over patches with the same leaf area index. Clouds are depicted in terms of their cloud condensate including liquid and ice phases. Note that as the cloud condensate is averaged in the $y$ direction, the apparent size of the 

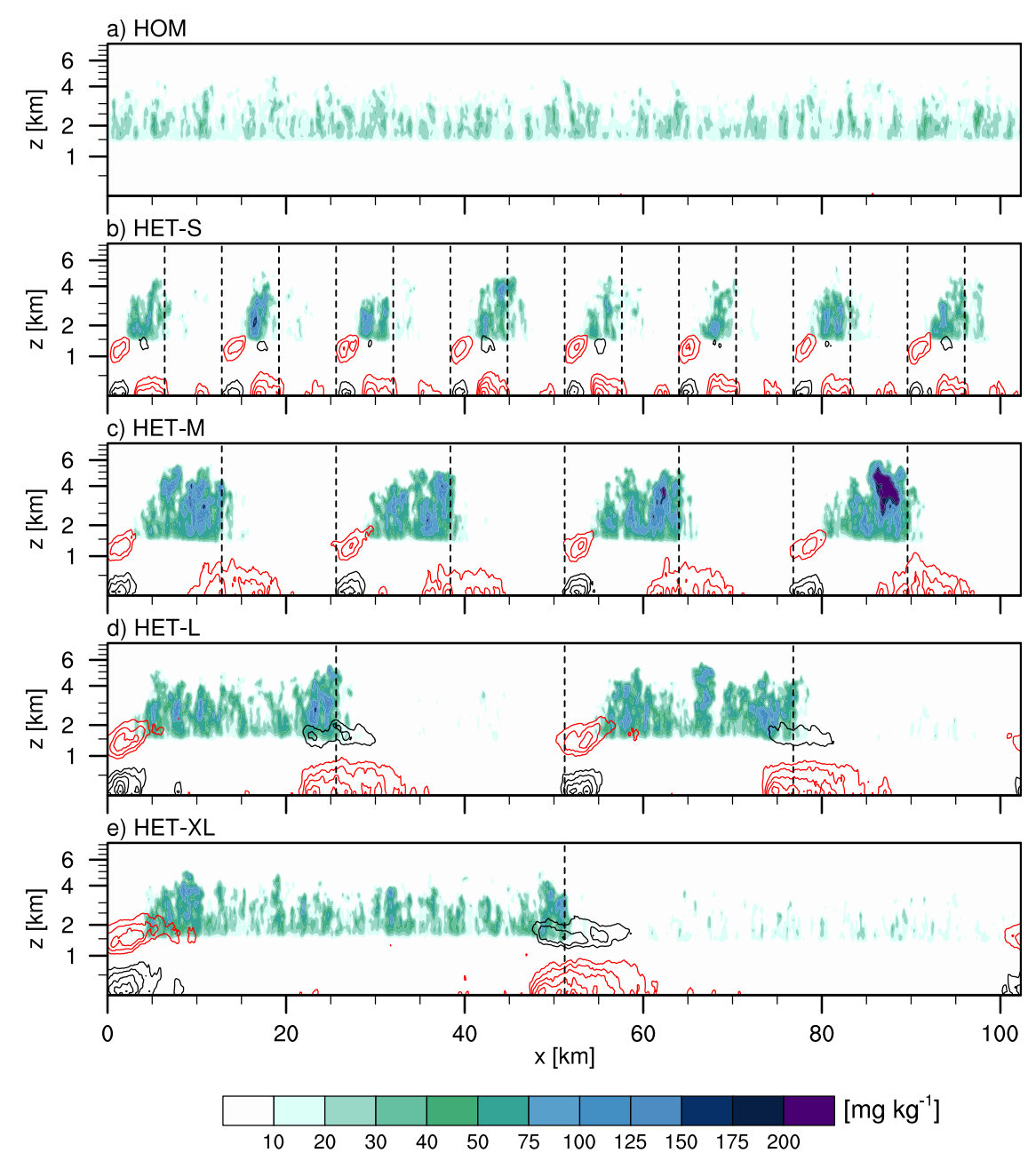

FIG. 8. Vertical cross section of cloud condensate (shaded contours in $\mathrm{mg} \mathrm{kg}^{-1}$ ) and horizontal wind (contour lines in $\mathrm{m} \mathrm{s}^{-1}$ with background wind removed, black colors in positive, and red colors in the negative $x$ direction, intervals of $0.25 \mathrm{~m} \mathrm{~s}^{-1}$ starting at $0.5 \mathrm{~m} \mathrm{~s}^{-1}$ ) for (a)-(e) different experiments at 1100 LST. HET-S resembles HOM and is not shown. All quantities at a given location $x$ are averaged in the $y$ direction over patches with the same leaf area index. Dashed lines indicate patch boundaries in the $y$ direction.

clouds in Fig. 8 does not correspond to the true size of the clouds, as defined in section 4 and displayed in Figs. 3 and 6. Figure 8 indicates that in HOM the clouds are randomly distributed over the whole domain whereas clouds are located directly above the warm patches in the HET experiments. This is consistent with Fig. 3. As discussed in Fig. 7a, HET-M features the largest clouds at 1100 LST.

The contour lines in Fig. 8 show the mesoscale circulations in the $u$ direction that develop due to the surface heterogeneity (see e.g., Avissar and Schmidt 1998; Baidya Roy et al. 2003). Locations with a sharp gradient in wind velocity indicate the position of the breeze front. Cloud development is enhanced at the leading edge of the breeze front where air is lifted and vertical velocities are larger (e.g., Garcia-Carreras et al. 2011). With time, the breeze fronts travel toward the patch center. The periodic heterogeneity in the experiments forces convergence of opposing breeze fronts, which end up colliding. The collision time is defined as the time when opposing horizontal winds from mesoscale circulations converge at the first time (see contour lines in Fig. 8) and a single updraft is produced (from cross sections of vertical velocities, not shown). Values of the collision time for the different experiments are listed in Table 1. Simulations with larger patch sizes display a later collision time. Note that the collision time is diagnosed from three-dimensional output, which is only available every $30 \mathrm{~min}$. The collision time is indicated with marker points in Fig. 7a. It is evident that in all simulations the 

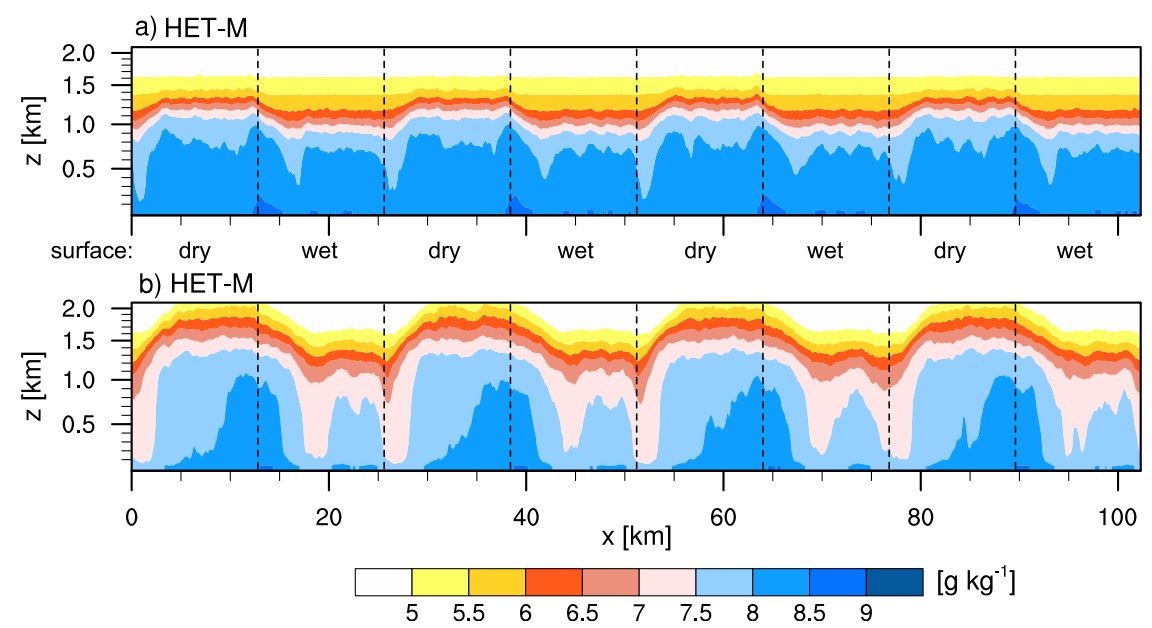

FIG. 9. Vertical cross sections of the total water content (shaded contours in $\mathrm{g} \mathrm{kg}^{-1}$ ) for HET-M at (a) 0900 and (b) 1100 LST. All quantities at a given location $x$ are averaged in the $y$ direction over patches with the same leaf area index. Dashed lines indicate patch boundaries in the $y$ direction.

cloud size reaches a local maximum near the collision time. Mesoscale circulations produce horizontally confined areas of updrafts surrounded by larger areas of sinking motion. The convergence of the breeze fronts with time produces higher vertical velocities and accelerates the cloud development until the breeze fronts collide. The accelerated cloud development corresponds to the above-normal growth rate of the cloud size in Fig. 7a as documented in section 4. After the collision of the breeze fronts those more favorable areas for cloud development become less important, the vertical motion weakens and the cloud size development proceeds at a slower rate. This is because the deep convective clouds, which at this time are exclusively located over the warm patches, produce cold downdrafts, cool the surface, and stabilize the atmosphere over the warm patches. As mesoscale circulations decay, the remaining clouds continue to grow at a slower rate. Figure $7 \mathrm{~b}$ shows the maximum vertical velocity and confirms a high level of agreement with the time evolution of the size of the largest could. Nevertheless, it is to note that in all heterogeneous experiments both maximum cloud size and maximum vertical velocity remain larger compared to the experiment with homogeneous surface conditions.

It follows that the introduced patch sizes are both favorable and detrimental to the formation of larger clouds. At first, through the effects of the triggered mesoscale circulations, heterogeneous surface conditions allow the formation of larger clouds that expand faster and should more rapidly transition to deep convection. But the finite size of those patches and thus of the updraft areas also sets a limit for the maximum size that a cloud can reach. The latter size may still be smaller than the size a cloud would need to reach $5.5 \mathrm{~km}$, meaning that a simulation with the largest clouds at a given time (e.g., HET-S) may not exhibit the fastest transition to deep convection. HET-M exhibits the fastest transition in Fig. 7a because the collision time (1130 LST) happens at the most optimal time with respect to the time clouds would transition without the help of mesoscale circulation, which is 1215 LST in HOM. The collision time in HET-XS and HET-S is too early, whereas it is too late in HET-L and HET-XL. This explains that there is no simple relationship between the transition time and the patch size. Other cases, for instance a drier case where the transition without the help of mesoscale circulation would happen later in time, could favor HET-L or HET-XL. As the precipitation onset follows the transition time (see section 3 ) the explanation also holds for the onset time of precipitation.

The previous explanation has emphasized the role of the convergence associated with the mesoscale circulations. Additionally, mesoscale circulations also act to bring moist air toward the warm surface patches increasing the amount of water available for cloud formation (Avissar and Schmidt 1998; van Heerwaarden and Vilà-Guerau de Arellano 2008). Figure 9 shows two vertical cross sections of total water mixing ratio for HET-M as an example, taken at 0900 and 1100 LST. At 0900 LST, when shallow convection starts, the boundary layer is deeper and the surface layer is drier above the warm patches than above the cold patches. Much of the available net radiation at the surface is released in form of sensible heat, warming the boundary layer. Later, at 1100 LST, the circulation advects moist air over the warm patches whereas the air above the cold patches is 


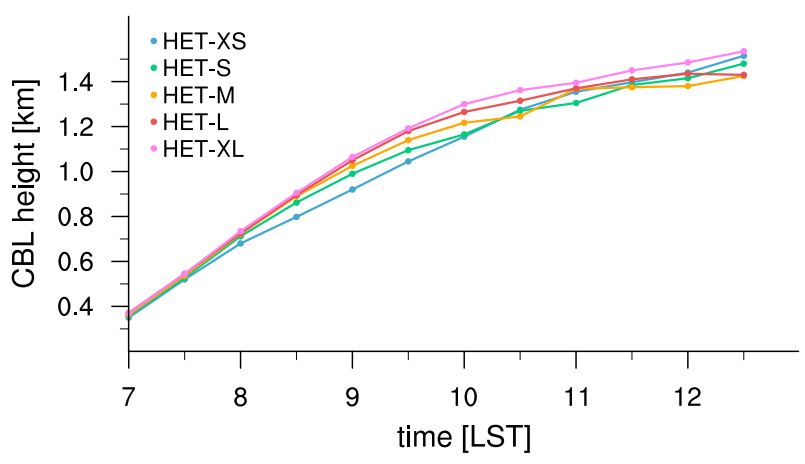

FIG. 10. Time series of mean boundary layer height sampled only above warm patches. Values are diagnosed from three-dimensional data every $30 \mathrm{~min}$.

slowly desiccated through the subsiding branch of the mesoscale circulation. The combined effect of both higher temperature and moisture results in a local maximum in the moist static energy (MSE) above the warm patches, especially close to the breeze front (not shown). These pockets of air with high MSE above the warm patches are a preferential location for the triggering of deep convection.

In some convective parameterizations the boundary layer height is used to determine the maximum initial cloud size in a given area (Graf and Yang 2007). The idea behind this concept is the fact that clouds grow from thermals with a maximum size limited by the height of the boundary layer itself. The boundary layer growth rate is known to be influenced by the surface buoyancy flux, which is largely controlled by the exchange of sensible heat. Consequently, in heterogeneous environments, the boundary layer may deepen locally (over the warmer patches) and trigger clouds if the condensation level is reached. This effect was found to be important to explain the sensitivity of the transition time to the amplitude of the imposed surface heterogeneity in Kang and Bryan (2011). In addition, the patch size itself may influence the boundary layer height and thus change the expected maximum cloud size.

Figure 10 shows a time series of the boundary layer height derived from mean temperature profiles conditionally sampled the over warm patches. We extend the maximum gradient method [see original definition in Sullivan et al. (1998)] to account for moist convection. The boundary layer height is defined at the intersection of the tangents to the maximum temperature gradient and to the minimum temperature of the mixed layer. The resulting boundary layer height is similar but slightly lower compared to the standard maximum gradient method. In the morning hours at 0700 LST all the experiments depict a very similar boundary layer height with a value near $350 \mathrm{~m}$. Later, at 0900 LST, the height reaches about $920 \mathrm{~m}$ in HET-XS whereas HET-XL features a height that is $145 \mathrm{~m}$ deeper. The boundary layer height appears proportional to the patch size. This is because at larger patch sizes the boundary layer in the center of a patch is less contaminated by its surrounding patches that are less convecting and exhibit weaker thermals. Kang and Bryan (2011) argued that over areas with deeper boundary layer convective, initiation occurs earlier and clouds become deeper. In their study they used an intermediate heterogeneity size of $16 \mathrm{~km}$ which is in between HET-M and HET-L. However, in the present study convective initiation happens first over areas with small patch sizes where the boundary layer is comparably shallow. This discrepancy might be explained by the fact that in all the HET simulations, the buoyancy flux is the same over the warm patch, which was not the case in Kang and Bryan (2011). The assumption that the size of the largest cloud (Fig. 7a) scales with the boundary layer height (Fig. 10) cannot be found. In fact, at 1000 LST the simulation with the shallowest boundary layer (HET-S) exhibits the largest clouds. At later times, the formation of widespread clouds reduces the difference in the boundary layer height between the simulations. Comparison of Fig. 7a and Fig. 10 again indicates that the boundary layer height is not a good predictor for the cloud size over heterogeneous surfaces as long as the patches sustain a similar surface buoyancy flux. Instead, the timing and strength of mesoscale convergence is a better proxy for the convective cloud development.

The so-derived effects of mesoscale circulations on the cloud size distribution may be included in a convective parameterization by modifying the entrainment. The entrainment is often viewed as inverse proportional to the cloud size that is investigated in Fig. 11. As an example, Fig. 11 shows the vertical profile of the bulk fractional entrainment rate at 1400 LST for the set of simulations. The entrainment of environmental air into the cloud core is diagnosed following Betts (1975) [see also de Rooy et al. (2013), their Eq. (18)]. In the cloud layer between 1.5 and $4 \mathrm{~km}$ the entrainment rate decreases with patch size. This is akin to the behavior of the diagnosed maximum cloud size at 1400 LST in Fig. 7a. In HET-XL the diagnosed entrainment is about $30 \%$ smaller compared to HOM. The observed variations in terms of entrainment rate are quite large (see Böing et al. 2012). Such large differences in the entrainment would speak for their inclusion in a convective parameterization.

\section{Summary and conclusions}

The timing of the transition from shallow to deep convection with the subsequential precipitation formation 


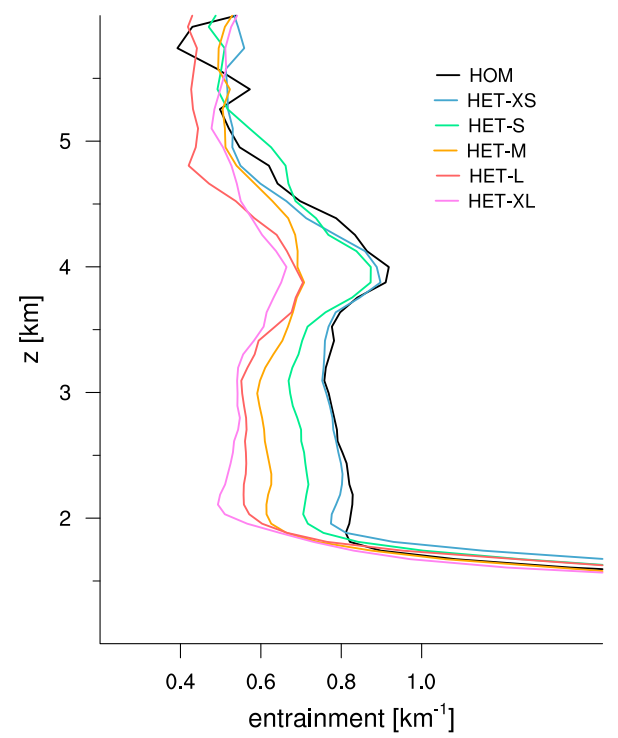

FIG. 11. Vertical profile of bulk fractional entrainment rate for different experiments at 1400 LST.

is still a major challenge for current weather and climate models. This study investigated the influence of surface heterogeneities on the convective development using large-eddy simulations. We focused in particular on the dependency of the evolving cloud size distribution on the horizontal scale of surface heterogeneity. One idealized case of the transition from shallow to deep convection, as typically occurring during summertime over midlatitude continental areas, has been simulated with large-eddy simulations. The large-eddy simulations have been coupled to a land surface model to introduce surface heterogeneities in a checkerboard pattern. Six experiments have been performed: five with various patch sizes within the mesoscale and one control experiment with homogeneous surface conditions.

In contrast to previous studies on the influence of surface heterogeneity on convective clouds, the adopted modeling setup allows for full interactions between the land surface, clouds, and radiation, at high resolution $(100 \mathrm{~m})$ and on a large domain $(100 \mathrm{~km})$. We showed that clouds counteract the initially higher potential for cloud formation over the warm patches by reducing the available energy at the surface. Hence, simulations without interactive land surface overestimate the surface fluxes below cloudy areas and thus may produce too strong mesoscale circulations.

The transition from shallow to deep convection occurred faster over heterogeneous surfaces; the experiment with the intermediate patch size exhibited the fastest transition. Consequently, also the onset of precipitation occurred earlier and the total accumulated precipitation increased with patch size. However, no linear relationship concerning the transition time, precipitation onset, and accumulated precipitation compared to the patch size could be determined.

Consideration of the cloud size distribution revealed further effects of the imposed land surface heterogeneity and important differences to homogeneous surface conditions. As over homogeneous surface conditions, the cloud size distribution follows a power law with a scale break at larger scales. During the shallow convective phase and transition phases, the power law remains similar but the scale break shifts to larger and larger clouds with time. The exponent of the power law lies near -2 and is independent of the imposed patch size. As a consequence, the cloud cover during the shallow and transition phases does not vary much between the simulations.

In contrast to the exponent of the power law, the scale break exhibits a clear dependency on the patch size. The scale break indicates the size of the largest clouds. These few but much larger clouds are important for the transition to deep convection as larger clouds entrain less and can more easily deepen and ultimately produce precipitation. The maximum size of the largest clouds at a given time depends on two main factors. On the one hand clouds expand in response to destabilization of the atmosphere caused by the diurnal cycle. This process is independent of the patch size and proceeds at the same pace in all the simulations. On the other hand the clouds feel the effect of the mesoscale circulations triggered by the surface heterogeneity. The convergence of the opposing breeze fronts yields an increase in the vertical velocity and an accelerated cloud development. This process depends upon the patch size. This leads to a faster-than-normal expansion of the clouds as long as the breeze fronts are converging. When breeze fronts collide the largest cloud size reaches a local maximum followed by a return toward the normal growth rate. This evolution can be found in all simulations but happens earlier in simulations with smaller patch sizes due to a shorter lifetime of the mesoscale circulations. Because clouds are generally larger in experiments with heterogeneous surface conditions, the diagnosed entrainment rate is reduced by up to $30 \%$ as compared to experiments with homogeneous surface conditions. Finally, mesoscale circulations also advect moisture from the cold patches onto the warm patches. This process increases the moist static energy and invigorates convection as a result of larger buoyancy.

Large-scale synoptic conditions such as background wind and atmospheric profiles of temperature and moisture may influence the obtained results. This study uses a low background wind and weak stability that both allow 
for a strong coupling between the land surface and convective clouds. We expect the results to hold for similar regimes as long as clouds are predominantly triggered over the warm patches. To which degree strong background winds affect land-atmosphere coupling remains controversial. Several studies are inconsistent with each other in this regard (Avissar and Schmidt 1998; Lynn et al. 2001; Raasch and Harbusch 2001), although it is expected that too strong background winds mask the effects of land surface heterogeneities. Also, the role of the chaotic nature of convection, whereby small differences in the initial conditions may be sufficient to affect the cloud and precipitation evolution, is not discussed here. Finally, the choice of parameterizations and model resolution may also influence the simulated clouds and precipitation. Therefore, it would be interesting to repeat the present study with a different large-eddy simulation model that employs a different parameterization scheme for clouds and precipitation. Despite the discussed limitations, the use of domainand time-averaged quantities as well as the obtained systematic behavior of the convective response across the different experiments give confidence that the results and mechanisms discussed in this study are characteristic for the general behavior of summertime convection in response to heterogeneous surface forcing.

The tendency of cloud-resolving models to exhibit a too late onset of precipitation might pinpoint to an incorrect representation of small-scale surface heterogeneity. The intermediate patch size accelerated the onset of deep convection by $75 \mathrm{~min}$, which corresponds to a transition time two-thirds that over a homogeneous surface. It is unlikely that the effects of these intermediate scales are properly represented in cloud-resolving models. Following Skamarock (2004), a grid spacing of $2.8 \mathrm{~km}$, as for instance used for operational weather forecasts at the German Weather Service (DWD), would correspond to an effective resolution of about $20 \mathrm{~km}$. On the other hand, large-scale general circulation models need to parameterize convection at all stages of its development. The effects described in this study may be best incorporated in the entrainment formulation as the entrainment rate is often viewed as inversely proportional to the cloud radius.

The complex interplay between cloud size and surface heterogeneity yields three main consequences for the transition from shallow to deep convection.

First, there is no simple relationship between transition time and patch size. The transition time depends upon the relative timing of the converging breeze fronts and the time it would take to transition in the absence of mesoscale circulations. If the collision happens too early or too late, the effects of the breeze on the cloud size and, hence, on the transition time will be rather modest. The same is true for the onset time of precipitation because the formation of noticeable precipitation requires deep clouds.

Second, the idea that larger clouds always grow faster and more rapidly transition to deep convection does not fully hold over heterogeneous surfaces. The largest clouds grow faster only until they reach a size equal to one-half of the patch size, that is, only as long as the breeze fronts have not collided. This means that a simulation that exhibits the largest clouds at a given time may not do so at a later time.

Third, the idea that the cloud size scales with the boundary layer height seems invalid over surfaces with different scales of heterogeneity. During the early stage of cloud development the height is proportional to the patch size and later independent of it. However, the cloud size evolution shows a different behavior. Therefore, convective parameterizations should not use the boundary layer height to determine the maximum cloud size in a given area with heterogeneous surface conditions.

The presented effects of land surface heterogeneity on the transition from shallow to deep convection emphasize the importance of including subgrid surface conditions in coarser-resolution models to adequately capture the transition between shallow and deep convection.

Acknowledgments. This research was supported by the Hans Ertel Center for Weather Research. A research network of universities, research institutes, and the Deutscher Wetterdienst funded by the BMVBS (Federal Ministry of Transport, Building and Urban Development, Germany). The simulations were performed using the facilities of the Deutsches Klimarechenzentrum. We thank Linda Schlemmer, Andreas Chlond, Thijs Heus, and Pierre Gentine for their helpful comments.

\section{REFERENCES}

Avissar, R., and T. Schmidt, 1998: An evaluation of the scale at which ground-surface heat flux patchiness affects the convective boundary layer using large-eddy simulations. J. Atmos. Sci., 55, 2666-2689, doi:10.1175/1520-0469(1998)055<2666: AEOTSA $>2.0 . \mathrm{CO} ; 2$.

Baidya Roy, S., C. P. Weaver, D. S. Nolan, and R. Avissar, 2003: A preferred scale for landscape forced mesoscale circulations? J. Geophys. Res., 108, 8854, doi:10.1029/2002JD003097.

Baldauf, M., A. Seifert, J. Förstner, D. Majewski, M. Raschendorfer, and T. Reinhardt, 2011: Operational convective-scale numerical weather prediction with the COSMO model: Description and sensitivities. Mon. Wea. Rev., 139, 3887-3905, doi:10.1175/ MWR-D-10-05013.1. 
Bechtold, P., J.-P. Chaboureau, A. Beljaars, A. K. Betts, M. Köhler, M. Miller, and J.-L. Redelsperger, 2004: The simulation of the diurnal cycle of convective precipitation over land in a global model. Quart. J. Roy. Meteor. Soc., 130, 3119 3137, doi:10.1256/qj.03.103.

Betts, A. K., 1975: Parametric interpretation of trade-wind cumulus budget studies. J. Atmos. Sci., 32, 1934-1945, doi:10.1175/ 1520-0469(1975)032<1934:PIOTWC > 2.0.CO;2.

Böing, S. J., H. J. J. Jonker, P. Siebesma, and W. W. Grabowski, 2012: Influence of the subcloud layer on the development of a deep convective ensemble. J. Atmos. Sci., 69, 2682-2698, doi:10.1175/JAS-D-11-0317.1.

Chen, F., and R. Avissar, 1994: Impact of land-surface moisture variability on local shallow convective cumulus and precipitation in large-scale models. J. Appl. Meteor., 33, 1382-1401, doi:10.1175/1520-0450(1994)033<1382:IOLSMV>2.0.CO;2.

Dalu, G., and R. Pielke, 1989: An analytical study of the sea breeze. J. Atmos. Sci., 46, 1815-1825, doi:10.1175/ 1520-0469(1989)046<1815:AASOTS > 2.0.CO;2.

Dawe, J. T., and P. H. Austin, 2012: Statistical analysis of an LES shallow cumulus cloud ensemble using a cloud tracking algorithm. Atmos. Chem. Phys., 12,1101-1119, doi:10.5194/acp-12-1101-2012.

de Rooy, W. C., and Coauthors, 2013: Entrainment and detrainment in cumulus convection: An overview. Quart. J. Roy. Meteor. Soc., 139, 1-19, doi:10.1002/qj.1959.

Fu, Q., and K. N. Liou, 1993: Parameterization of the radiative properties of cirrus clouds. J. Atmos. Sci., 50, 2008-2024, doi:10.1175/1520-0469(1993)050<2008:POTRPO >2.0.CO;2.

Garcia-Carreras, L., D. J. Parker, and J. H. Marsham, 2011: What is the mechanism for the modification of convective cloud distributions by land surface induced flows? J. Atmos. Sci., 68 , 619-634, doi:10.1175/2010JAS3604.1.

Graf, H.-F., and J. Yang, 2007: Evaluation of a new convective cloud field model: Precipitation over the maritime continent. Atmos. Chem. Phys., 7, 409-421, doi:10.5194/acp-7-409-2007.

Heus, T., and A. Seifert, 2013: Automated tracking of shallow cumulus clouds in large domain, long duration Large Eddy Simulations. Geosci. Model Dev. Discuss., 6, 2287-2323, doi:10.5194/gmdd-6-2287-2013.

_ and Coauthors, 2010: Formulation of the Dutch Atmospheric Large-Eddy Simulation (DALES) and overview of its applications. Geosci. Model Dev., 3, 415-444, doi:10.5194/ gmd-3-415-2010.

Hohenegger, C., and B. Stevens, 2013: Preconditioning deep convection with cumulus congestus. J. Atmos. Sci., 70, 448-464, doi:10.1175/JAS-D-12-089.1.

— , P. Brockhaus, C. S. Bretherton, and C. Schär, 2009: The soil moisture-precipitation feedback in simulations with explicit and parameterized convection. J. Climate, 22, 5003-5020, doi:10.1175/2009JCLI2604.1.

Huang, H.-Y., and S. A. Margulis, 2013: Impact of soil moisture heterogeneity length scale and gradients on daytime coupled land-cloudy boundary layer interactions. Hydrol. Processes, 27, 1988-2003, doi:10.1002/hyp.9351.

Jarvis, P. G., 1976: The interpretation of the variations in leaf water potential and stomatal conductance found in canopies in the field. Philos. Trans. Roy. Soc. London, 273, 593-610, doi:10.1098/rstb.1976.0035.

Kain, J. S., 2004: The Kain-Fritsch convective parameterization: An update. J. Appl. Meteor., 43, 170-181, doi:10.1175/ 1520-0450(2004)043<0170:TKCPAU > 2.0.CO;2.

Kang, S.-L., and G. H. Bryan, 2011: A large-eddy simulation study of moist convection initiation over heterogeneous surface fluxes. Mon. Wea. Rev., 139, 2901-2917, doi:10.1175/ MWR-D-10-05037.1.

Khairoutdinov, M., and D. Randall, 2006: High-resolution simulation of shallow-to-deep convection transition over land. J. Atmos. Sci., 63, 3421-3436, doi:10.1175/JAS3810.1.

Koster, R. D., and Coauthors, 2004: Regions of strong coupling between soil moisture and precipitation. Science, 305, 11381140, doi:10.1126/science.1100217.

Kuang, Z., and C. S. Bretherton, 2006: A mass-flux scheme view of a high-resolution simulation of a transition from shallow to deep cumulus convection. J. Atmos. Sci., 63, 1895-1909, doi:10.1175/JAS3723.1.

Kühnlein, C., C. Keil, G. C. Craig, and C. Gebhardt, 2014: The impact of downscaled initial condition perturbations on convective-scale ensemble forecasts of precipitation. Quart. J. Roy. Meteor. Soc., 140, 1552-1562, doi:10.1002/qj.2238.

Lynn, B., W.-K. Tao, and P. Wetzel, 1998: A study of landscapegenerated deep moist convection. Mon. Wea. Rev., 126, 928-942, doi:10.1175/1520-0493(1998)126<0928:ASOLGD>2.0.CO;2.

_ - _ and F. Abramopoulos, 2001: A parameterization for the triggering of landscape-generated moist convection. Part I: Analysis of high-resolution model results. J. Atmos. Sci., 58, 575-592, doi:10.1175/1520-0469(2001)058<0575: APFTTO $>2.0 . \mathrm{CO} ; 2$.

Neggers, R. A. J., 2009: A dual mass flux framework for boundary layer convection. Part II: Clouds. J. Atmos. Sci., 66, 1489-1506, doi:10.1175/2008JAS2636.1.

, H. J. J. Jonker, and P. Siebesma, 2003: Size statistics of cumulus cloud populations in large-eddy simulations. J. Atmos. Sci., 60, 1060-1074, doi:10.1175/1520-0469(2003)60<1060: SSOCCP $>2.0 . \mathrm{CO} ; 2$.

Petch, J. C., R. Brown, and M. E. B. Gray, 2002: The impact of horizontal resolution on the simulations of convective development over land. Quart. J. Roy. Meteor. Soc., 128, 20312044, doi:10.1256/003590002320603511.

Pielke, R. A., 2001: Influence of the spatial distribution of vegetation and soils on the prediction of cumulus convective rainfall. Rev. Geophys., 39, 151-177, doi:10.1029/1999RG000072.

Pincus, R., and B. Stevens, 2009: Monte Carlo spectral integration: A consistent approximation for radiative transfer in large eddy simulations. J. Adv. Model. Earth Syst., 1, 1-9, doi:10.3894/ JAMES.2009.1.1.

$\longrightarrow$, and — 2013: Paths to accuracy for radiation parameterizations in atmospheric models. J. Adv. Model. Earth Syst., 5, 225-233, doi:10.1002/jame.20027.

Plant, R. S., and G. C. Craig, 2008: A stochastic parameterization for deep convection based on equilibrium statistics. J. Atmos. Sci., 65, 87-105, doi:10.1175/2007JAS2263.1.

Raasch, S., and G. Harbusch, 2001: An analysis of secondary circulations and their effects caused by small-scale surface inhomogeneities using large-eddy simulation. Bound.-Layer Meteor., 101, 31-59, doi:10.1023/A:1019297504109.

Robinson, F. J., S. C. Sherwood, and Y. Li, 2008: Resonant response of deep convection to surface hot spots. J. Atmos. Sci., 65, 276-286, doi:10.1175/2007JAS2398.1.

Savic-Jovcic, V., and B. Stevens, 2008: The structure and mesoscale organization of precipitating stratocumulus. J. Atmos. Sci., 65 , 1587-1605, doi:10.1175/2007JAS2456.1.

Schlemmer, L., and C. Hohenegger, 2014: The formation of wider and deeper clouds as a result of cold-pool dynamics. J. Atmos. Sci., 71, 2842-2858, doi:10.1175/JAS-D-13-0170.1.

- — - J. Schmidli, C. S. Bretherton, and C. Schär, 2011: An idealized cloud-resolving framework for the study of 
midlatitude diurnal convection over land. J. Atmos. Sci., 68 , 1041-1057, doi:10.1175/2010JAS3640.1.

Seifert, A., and K. D. Beheng, 2006: A two-moment cloud microphysics parameterization for mixed-phase clouds. Part 2: Maritime vs. continental deep convective storms. Meteor. Atmos. Phys., 92, 67-82, doi:10.1007/s00703-005-0113-3.

Skamarock, W. C., 2004: Evaluating mesoscale NWP models using kinetic energy spectra. Mon. Wea. Rev., 132, 3019-3032, doi:10.1175/MWR2830.1.

Stevens, B., and Coauthors, 2005: Evaluation of large-eddy simulations via observations of nocturnal marine stratocumulus. Mon. Wea. Rev., 133, 1443-1462, doi:10.1175/ MWR2930.1.

Su, H., M. F. McCabe, and E. F. Wood, 2005: Modeling evapotranspiration during SMACEX: Comparing two approaches for local- and regional-scale prediction. J. Hydrometeor., 6, 910-922, doi:10.1175/JHM466.1.
Sullivan, P., C.-H. Moeng, B. Stevens, D. Lenschow, and S. Mayor, 1998: Structure of the entrainment zone capping the convective atmospheric boundary layer. J. Atmos. Sci., 55, 3042-3064, doi:10.1175/1520-0469(1998)055<3042:SOTEZC >2.0.CO;2.

Teuling, A. J., and Coauthors, 2010: Contrasting response of European forest and grassland energy exchange to heatwaves. Nat. Geosci., 3, 722-727, doi:10.1038/ngeo950.

van Heerwaarden, C. C., and J. Vilà-Guerau de Arellano, 2008: Relative humidity as an indicator for cloud formation over heterogeneous land surfaces. J. Atmos. Sci., 65, 3263-3277, doi:10.1175/2008JAS2591.1.

Wood, R., and P. R. Field, 2011: The distribution of cloud horizontal sizes. J. Climate, 24, 4800-4816, doi:10.1175/ 2011JCLI4056.1.

Wu, C.-M., B. Stevens, and A. Arakawa, 2009: What controls the transition from shallow to deep convection? J. Atmos. Sci., 66, 1793-1806, doi:10.1175/2008JAS2945.1. 